\title{
Desempenho ambiental e nível de sustentabilidade de uma empresa do setor médico-hospitalar no sul do Rio Grande do Sul, Brasil
}

\section{Guilherme Pereira Schoeler ${ }^{1}, *$, Jéssica Torres dos Santos ${ }^{1}$, Aryane Araujo Rodrigues ${ }^{1}$, Thales Castilhos de Freitas ${ }^{1}$, Jéssica da Rocha Alencar Bezerra de Holanda ${ }^{1}$, Robson Andreazza $^{2}$, Maurizio Silveira Quadro' ${ }^{2}$, Tirzah Moreira Siqueira $^{2}$, Rafael Beltrame ${ }^{2}$, Diuliana Leandro ${ }^{2}$ e Andréa Souza Castro ${ }^{2}$}

\begin{abstract}
${ }^{1}$ Programa de Pós-Graduação em Ciências Ambientais. Universidade Federal de Pelotas. Centro de Engenharias. Rua Benjamin Constant, 989. Porto Pelotas-RS, Brasil (CEP 96010-020). *E-mail: guilherme.schoeler@gmail.com.

${ }^{2}$ Universidade Federal de Pelotas. Centro de Engenharias. Curso de Engenharia Ambiental e Sanitária. Rua Benjamin Constant, 989. Porto Pelotas-RS, Brasil (CEP 96010-020).
\end{abstract}

Resumo. Para acompanhar as mudanças no desenvolvimento econômico, que tem sido cada vez mais associado à sustentabilidade, empresas vêm buscando novas concepções para auxiliar na gestão de suas questões ambientais, empregando soluções que melhorem a eficiência de seus processos e reduzam os impactos ambientais de suas atividades. Assim, o objetivo deste estudo foi verificar o desempenho ambiental de uma empresa do setor de produtos médico-hospitalares, bem como avaliar o seu nível de Sustentabilidade Empresarial (NSE) e propor melhorias. Foi realizado um diagnóstico ambiental da empresa, utilizando uma lista de verificação (checklist) frequentemente utilizada na fase de preparação de auditorias ambientais. Nesta lista, que contou com o levantamento observacional dos aspectos e possíveis impactos ambientais, bem como a aplicação de um questionário com 75 questões sobre controle gerencial, gestão de efluentes líquidos, gestão de resíduos, gestão e emissões atmosféricas, gestão de ruídos, gestão de materiais e prevenção e controle de vazamentos. A análise dos resultados mostrou que a gestão de resíduos é a categoria com melhores práticas e políticas ambientais, além de contar com uma gestão consolidada com metas de redução de resíduos. O NSE médio da empresa foi enquadrado como satisfatório, demonstrando sua adequação às questões ambientais, principalmente pelo cumprimento da legislação de licenciamento ambiental e normas de qualidade, mesmo não possuindo certificações ambientais. Com isso, sugere-se a implementação de
Recebido

$29 / 09 / 2020$

Aceito

$28 / 11 / 2020$

Disponível on line

$30 / 11 / 2020$

Publicado

$31 / 12 / 2020$

Acesso aberto

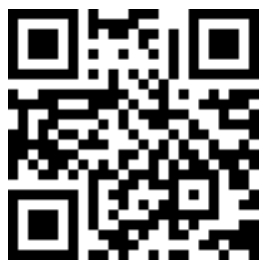

0000-0002-5289-0602 Guilherme Pereira Schoeler

ISSN 2359-1412/RBGAS-2020-0146/2020/7/17/26/1455

Rev. Bras. Gest. Amb. Sustent.

http://revista.ecogestaobrasil.net 
um sistema de gestão integrado com política ambiental, além de recomendações pontuais como incluir o aproveitamento de água da chuva nas instalações da empresa e a realização de ações de educação e de promoção da conscientização ambiental, direcionadas aos funcionários e a comunidade da região de influência do empreendimento.

Palavras-chave: Aspectos e impactos ambientais; Método GAIA; Lista de verificação; Gestão ambiental empresarial.

Abstract. Environmental performance and level of
sustainability of a medical-hospital equipment company in the
southern Rio Grande do Sul, Brazil. Keeping up with changes taking place in economic development, which have been increasingly associated with sustainability, requires companies to find new concepts to help to manage their environmental issues by adopting solutions capable of improving the efficiency of their processes, as well as of reducing the environmental impacts caused by their activity. Thus, the current study aims to analyze the environmental performance of a company in the medical and hospital product sector, as well as to assess its Corporate Sustainability Level (CSL) and suggest improvements. An environmental diagnosis of the company was carried out based on a checklist often used in the preparation stage of environmental audits. The checklist encompassed the observational survey of environmental aspects and likely environmental impacts, as well as the application of a questionnaire comprising 75 questions about management control, liquid effluent management, waste management, atmospheric management and emissions, noise management, materials' management, and leak prevention and control. Result analyses have shown that waste management was the category presenting the best environmental practices and policies, as well as consolidated management based on waste reduction targets. The company's mean CSL was classified as satisfactory; it was suitable for environmental matters, mainly because it complied with the environmental licensing legislation and quality standards, although the company does not have environmental certifications. Thus, the current study suggests that the company should implement a management system integrated with environmental policies, as well as recommends using rainwater in the company's facilities and taking educational and environmental awareness promotion actions focused on its employees and the community living in its region of influence.

Keywords: Environmental aspects and impacts; GAIA method; Checklist; Entrepreneurial environmental management.
(1) 0000-0002-6544-2286

Jéssica Torres dos

Santos

(1) 0000-0002-5338-682X

Aryane Araujo

Rodrigues

D 0000-0001-7362-5237

Thales Castilhos de

Freitas

(D) 0000-0002-5521-0238

Jéssica da Rocha

Alencar Bezerra de

Holanda

D) 0000-0001-9211-9903

Robson Andreazza

(1) 0000-0001-8236-7479

Maurizio Silveira

Quadro

D) 0000-0002-6576-0217

Tirzah Moreira

Siqueira

D 0000-0001-6352-0052

Rafael Beltrame

(D) 0000-0002-8092-5550

Diuliana Leandro

D 0000-0003-1989-684X

Andréa Souza Castro 


\section{Introdução}

Os problemas ambientais provocados pelo ser humano decorrem do uso do meio ambiente visando obter os recursos necessários para produção de bens e serviços (Barbieri, 2016). Conforme Dias (2017), nos últimos 300 anos o mundo passou por um processo de transformação e desenvolvimento tecnológico onde foram feitas grandes descobertas, aumentando cada vez mais a sua capacidade de produção, porém, também foi o período em que o ser humano gerou os meios que podem levá-lo à extinção.

0 nível de produção que o meio ambiente pode suportar tem gerado grandes debates desde a década de 1970 (Nascimento, 2012). No entanto, somente depois um grande número de acidentes ambientais resultantes de práticas inadequadas é que o conhecimento e a preocupação da população sobre essa questão têm aumentado, manifestados através da aprovação de diversas regulamentações (Campos e Melo, 2008; Mazzer e Cavalcanti, 2013; Barbieri, 2016).

Nas últimas décadas, o cenário mundial de avanços tecnológicos tem enfatizado assuntos relacionados à sustentabilidade e preservação ambiental, em que a gestão ambiental se tornou uma importante ferramenta de modernização, competitividade e prevenção de danos para as organizações (Barata et al., 2007; Campos e Melo, 2008). Ser uma empresa sustentável consiste em tomar um conjunto de ações que visam o respeito ao meio ambiente e a sociedade por meio de atitudes e práticas éticas que visem seu crescimento (Silveira, 2011), a exemplo do uso de tecnologias ao final do processo produtivo para reter a contaminação gerada ou a adoção de atividades de prevenção da contaminação ao longo do processo produtivo, que visam aumentar a eficiência dos processos, reduzir custos e desperdícios, desenvolver a recirculação de recursos e introduzir inovações no setor (Dias, 2017; Santos et al., 2018).

No comércio e indústria, a certificação ambiental tem assumido um papel cada vez maior, visto o grande investimento das organizações para implantação de selos ambientais e certificação dos sistemas ISO com reconhecimento internacional, que sigam as normas ambientais e de qualidade, tornando as empresas diferenciadas nas relações de mercado (Dias, 2017; Vanderley, 2019). Grael e Oliveira (2010), afirmam que o sistema de gestão da qualidade proporciona a melhoria contínua e a racionalização de projetos, processos e produtos, de acordo com as necessidades da organização, enquanto que o sistema de gestão ambiental possibilita processos mais sustentáveis e redução dos custos pela oportunidade de melhor utilização dos recursos naturais e aplicação de conceitos de produção mais limpa.

A conexão entre as normas de qualidade (ISO 9001) e ambiental (ISO 14001) contribui para o desenvolvimento de um padrão de gerenciamento compatível através de um Sistema de Gestão Integrado (SGI), favorecendo a sinergia necessária para as organizações alcançarem os requisitos em prol da sustentabilidade (Pheng e Tan, 2005). Conforme mencionado por Fagundes e Scheriber (2017), a unificação das dimensões ambiental, econômica e social é essencial para analisar a sustentabilidade empresarial de forma a contribuir desde o desenvolvimento local ao global. A integração dos sistemas e implantação de um SGI é uma alternativa eficaz para a redução de custos relacionados à organização e manutenção de diferentes sistemas separados (Godini e Valverde, 2001; Stefano, 2009). O SGI utiliza a base comum de todos os outros sistemas para trabalharem conjuntamente, estimula a obtenção de resultados precisos, representando economia de tempo, esforço humano e recursos técnico-financeiros quando comparado com vários sistemas gerenciados separadamente (Oliveira, 2013).

No segmento industrial as empresas de materiais médicos, hospitalares e odontológicos ocupam grande participação no eixo da saúde, uma vez são as que mais incorporam plataformas tecnológicas por meio da Pesquisa e Desenvolvimento (P\&D) para fabricação de seus produtos que englobam desde o conjunto de produtos 
eletromédicos e instrumentos cirúrgicos até materiais de consumo médico-hospitalar (Pieroni et al., 2010; Mendes e Toledo, 2012). De acordo a Associação Brasileira da Indústria de Artigos e Equipamentos Médicos, Odontológicos, Hospitalares e de Laboratório, a produção nacional acumulada do setor em 2018 foi de R\$ 10 milhões gerando mais de 59 mil empregos (ABIMO, 2020). A estabilidade do setor está relacionada a investimentos em saúde pública pela maioria dos países, devido ao aumento da expectativa de vida e doenças crônico-degenerativas, associadas a altos custos de tratamento (Piorini et al., 2010). No Brasil, que possivelmente detém o maior sistema público de saúde no mundo, o Complexo Econômico Industrial da Saúde (CEIS) é um dos pilares para a redução da vulnerabilidade ao acesso à saúde que busca explorar o potencial econômico e social do setor por meio do poder de compra do Estado e crescimento sustentável (Brasil, 2017).

Um dos princípios básicos da gestão é realizar avaliações quali-quantitativas periódicas da conformidade legal da empresa. Assim, a auditoria ambiental surge como uma ferramenta essencial, que pode ser aplicada interna (própria organização) e externa (realizada por outra organização) em produtos, processos e sistemas, como forma de verificação, e em muitos casos certificação, do que foi previamente estabelecido na política, objetivos e metas da empresa (La Rovere et al., 2011; Barbieri, 2016). Inicialmente, as auditorias ambientais procuravam assegurar que as empresas se adequassem à legislação, dentro de uma postura defensiva, buscando identificar possíveis problemas relacionados às multas, indenizações e outras penalidades legais. Porém, as organizações começaram a realizar auditorias voluntárias, não concebidas apenas como fiscalização, e estimuladas cada vez mais por órgãos governamentais (Campos e Lerípio, 2009; Barbieri, 2016). Atualmente as auditorias são vistas como ações de melhoria contínua para identificação de responsabilidade profissional, socioambiental e financeira das organizações (Rosa et al., 2012).

Conforme Araujo et al. (2006), sustentabilidade organizacional são as ações que as organizações realizam, à exemplo de programas sociais e à redução dos seus impactos ambientais, mantendo-se economicamente viável no mercado. Entretanto, Teles et al. (2016) mencionam que uma das dificuldades encontradas no desenvolvimento sustentável é a necessidade de conhecer o nível de sustentabilidade dos diferentes setores da sociedade, a fim de determinar quais mudanças conduzem à esse caminho, pois dentre os benefícios de avaliar e reportar a sustentabilidade, estão: a legitimação das atividades, dos produtos e dos serviços corporativos; aumento da reputação corporativa e do valor da marca; vantagem competitiva; comparação e benchmarking com concorrentes; motivação dos funcionários e aumento da transparência e responsabilidade dentro da empresa.

Deste modo, é possível que as empresas representem um dos principais aliados para o alcance do desenvolvimento sustentável, adotando novas concepções de gestão ambiental, que tem como objetivo estabelecer políticas de qualidade, ambientais e de segurança, pois assim o setor produtivo passa a ser visto como contribuinte para soluções que visem a redução de impactos negativos no meio ambiente e desenvolvimento econômico (La Rovere et al., 2011). Segundo Paz (2015), realizar uma análise sistêmica das organizações, utilizando, por exemplo, auditorias e indicadores que buscam um entendimento de todos os processos envolvidos, demonstra caminhos que fomentem uma transformação das empresas em direção ao desenvolvimento sustentável.

Neste sentido, considerando a importância do segmento da empresa e a necessidade cada vez maior de investigar e estabelecer um controle sobre os impactos ambientais do setor industrial, este estudo teve como objetivo avaliar o desempenho ambiental de uma empresa do setor de produtos médico-hospitalares bem como o seu Nível de Sustentabilidade Empresarial (NSE). 


\section{Materiais e métodos}

O estudo foi realizado em uma empresa do setor médico-hospitalar, sediada no município de Pelotas, extremo sul do Rio Grande do Sul, Brasil. A organização opera no ramo de produtos, dispositivos e equipamentos médicos e hospitalares, fornecendo-os para mais de 2000 hospitais brasileiros. A escolha da organização se deu em função de critérios pré-estabelecidos como facilidade de acesso, abertura à visita técnica, ramo de mercado e importância econômica para a região.

0 diagnóstico ambiental na empresa foi realizado por meio de uma lista de verificação (checklist) geralmente aplicada em auditorias ambientais. Sendo assim, o processo contou com quatro etapas subsequentes: planejamento, preparação, aplicação da lista de verificação, visita em loco e elaboração do relatório final. Neste processo buscou-se analisar e entender o sistema de gestão empresarial e as práticas de gestão ambiental da organização.

O planejamento e a preparação da auditoria foram realizados conforme descrito por La Rovere et al. (2011), utilizando o método da lista de verificação (checklist) para coletar dados, que consiste em uma lista de questões com respostas de "sim", "não" ou "não se aplicam", onde o "entrevistador" é levado a fazer perguntas bem mais do que rever e/ou examinar processos. Por se tratar de um modelo extenso, de grande abrangência e diversidade das verificações, foi realizada a seleção das questões, a fim de definir aquelas que seriam de maior interesse para o diagnóstico ambiental e teriam maior relação com os processos da empresa, conforme indicado no manual.

A execução do diagnóstico ambiental foi realizada em uma visita técnica na unidade de produção da empresa, em julho de 2019. Aplicou-se 75 questões selecionadas do checklist aos colaboradores da empresa e responsáveis pelo setor da qualidade e questões ambientais, divididas em: controle gerencial, gestão de materiais, gestão de efluentes líquidos, gestão de resíduos, gestão e emissões atmosféricas, gestão de ruídos e prevenção e controle de vazamentos. Uma das técnicas utilizada para este processo é chamada de "amostragem dirigida", que de acordo com La Rovere et al. (2011), abrange somente uma determinada porção da população, sendo selecionada em função de informações importantes previamente obtidas e, portanto, comumente utilizada para setores problemáticos.

Além disso, para avaliar o desempenho da empresa frente ao diagnóstico qualitativo, utilizou-se uma adaptação do modelo de Gerenciamento de Aspectos e Impactos Ambientais (GAIA), que, segundo Lerípio (2001), possui um caráter inovador ao criar uma forma sistematizada de gerenciamento ambiental de organizações. Conforme Santos et al. (2015), o método não possui limitações de aplicação com relação ao tipo ou porte da empresa, pode ser aplicado a qualquer tipo de processo produtivo, e serve como um instrumento de melhoria de desempenho ambiental, tendo em vista que permite avaliar quantitativamente o Nível de Sustentabilidade Empresarial (NSE).

Uma vez contabilizado o número de observações de cada tema, as respostas foram utilizadas como dados de entrada na Equação 1, proposta por Lerípio (2001) e descrita por Richard Júnior (2006):

$$
N S E(\%)=\frac{\left(N^{o} \text { de respostas SIM } * 100\right)}{\left(N^{\circ} \text { total de respostas do tema }-N^{o} \text { de respostas } N S A\right)}(1)
$$

Onde, NSE: Nível de Sustentabilidade Empresarial, NSA: respostas às perguntas daquele tema que Não Se Aplicam à organização dentro daquele tema. 
Este método indica pontos a ser melhorados pela organização, pois quanto melhor o aproveitamento dos recursos e menor o impacto ambiental, maior será o nível de sustentabilidade, ou seja, mais próximo de um SGA a empresa encontra-se e maior será a contribuição positiva para a biosfera (Teles et al., 2016; Agustini e Giannetti, 2018).

A análise dos resultados foi realizada em planilha eletrônica, enquadrando as respostas nos níveis de sustentabilidade com base nas classes dispostas na Tabela 1.

Tabela 1. Referencial para classificação do NSE.

\begin{tabular}{|l|c|}
\hline Resultado (\%) & NSE \\
\hline Menor que 30\% & Crítico \\
\hline Entre 30\% e 50\% & Péssimo \\
\hline Entre $51 \%$ e $70 \%$ & Adequado \\
\hline Entre $71 \%$ e $90 \%$ & Bom \\
\hline Superior a $90 \%$ & Excelente \\
\hline
\end{tabular}

Fonte: Adaptado de Lerípio (2001).

\section{Resultados e discussão}

De acordo com a missão, visão e valores da empresa o foco principal está relacionado à inovação e qualidade dos seus produtos e, a única menção às questões ambientais está nos valores da empresa. Além dos requisitos obrigatórios por lei, como a RDC ANVISA no 16/2013, que estabelece as boas práticas de fabricação de produtos médicos e produtos para diagnóstico de uso in vitro (Brasil, 2013), e a Lei no 6.360/1976, que dispõe sobre a vigilância sanitária a que ficam sujeitos os medicamentos, as drogas, os insumos farmacêuticos e correlatos, cosméticos, saneantes e outros produtos (Brasil, 1976), a empresa também está certificada quanto à ABNT NBR ISO 13485:2016, relacionada à gestão para produtos da saúde (ABNT, 2016).

Na Tabela 2, são apresentados os percentuais do NSE de cada tema dentro das áreas e suas respectivas classificações, conforme proposto por Lerípio (2001) e descrita por Richard Júnior (2006). Com base na auditoria realizada e nas 75 questões respondidas, calculou-se o NSE. Ao total, 70\% das questões foram respondidas com "sim" e 71\% das áreas foram enquadrados em um NSE "bom" ou "excelente". Estes resultados refletem boas práticas da empresa com relação ao meio ambiente, contemplando os interesses e importância dos diversos temas para a empresa. Para Hrdlicka (2018), as boas práticas ambientais são fundamentais para a sobrevivência e sucesso empresarial no atual e futuro cenário econômico.

\section{Controle gerencial e gestão de materiais}

Em relação à área de controle gerencial, foram aplicadas trinta e oito questões relacionadas à política ambiental, desempenho, metas e programas de responsabilidade ambiental, além de questionar se a empresa está em conformidade legal. A empresa não possui setor ambiental específico ou política ambiental, embora exista esta responsabilidade. Estes assuntos são tratados dentro da gestão da qualidade, que é responsável também pelos custos e investimentos na área ambiental, com ações relacionadas à reciclagem e conservação de energia. 
Tabela 2. NSE das áreas e temas de uma empresa do setor de produtos, dispositivos e equipamentos médicos e hospitalares do sul do Brasil.

\begin{tabular}{|c|c|c|c|}
\hline Área & Tema & $\begin{array}{c}\text { Percentual } \\
(\%) \\
\end{array}$ & $\begin{array}{c}\text { Nível de } \\
\text { sustentabilidade } \\
\end{array}$ \\
\hline \multirow{12}{*}{ Controle gerencial } & Política ambiental & 0 & Crítico \\
\hline & Desempenho ambiental & 50 & Péssimo \\
\hline & Estrutura e responsabilidade & 100 & Excelente \\
\hline & $\begin{array}{l}\begin{array}{l}\text { Gerenciamento de pessoal e } \\
\text { treinamento }\end{array} \\
\end{array}$ & 50 & Péssimo \\
\hline & Relações públicas & 33,33 & Péssimo \\
\hline & $\begin{array}{l}\text { Investimentos e conformidades } \\
\text { legais }\end{array}$ & 100 & Excelente \\
\hline & Consumidores & 0 & Crítico \\
\hline & Seguro e consumo de energia & 100 & Excelente \\
\hline & Material de escritório & 66,67 & Adequado \\
\hline & Processos de produção e operação & 100 & Excelente \\
\hline & Transporte e distribuição & 0 & Crítico \\
\hline & Higiene e saúde ocupacional & 100 & Excelente \\
\hline Gestão de materiais & $\begin{array}{ll}\text { Conformidades } & \text { legais, } \\
\text { gerenciamento e controle } & \\
\end{array}$ & 72,73 & Bom \\
\hline Gestão de efluentes & $\begin{array}{l}\text { Consumo de água, } \\
\begin{array}{l}\text { sanitário efluentes } \\
\text { pluviais }\end{array}\end{array}$ & 100 & Excelente \\
\hline Gestão de resíduos & $\begin{array}{l}\text { Gerenciamento, transporte } \\
\text { disposição final }\end{array}$ & 100 & Excelente \\
\hline Gestão de ruídos & Identificação e controle & 100 & Excelente \\
\hline $\begin{array}{lr}\text { Prevenção } & \mathrm{e} \\
\text { controle } & \mathrm{de} \\
\text { vazamentos } & \\
\end{array}$ & Identificação e treinamento & 100 & Excelente \\
\hline
\end{tabular}

Os objetivos e metas da empresa relacionados ao desempenho ambiental não são evidentes, visto que não há política ambiental, sendo somente metas relacionadas à qualidade dos seus produtos. Nos setores visitados, foi constatado que os funcionários são informados, conscientizados e atuam de acordo com as decisões relativas às questões ambientais, havendo locais adequados para disposição de resíduos. Não foi verificada existência de incentivos aos colaboradores para participarem de atividades ambientais voluntárias, no entanto, há treinamento aos funcionários quanto às práticas de segurança, qualidade e reincorporação de materiais plásticos e silicone na cadeia produtiva.

Para Capelari et al. (2013), um fenômeno considerado convincente no combate à degradação ambiental é a mudança de comportamento empresarial, em especial no que se refere ao comportamento das indústrias, consistindo no aparelhamento empresarial composto por instrumentos como profissionais e departamento especializado, certificação ambiental, produção mais limpa, tudo com o propósito de criar vantagens competitivas. Em uma empresa privada de energia no Ceará, Brasil, a implementação de atividades ambientais dentro um calendário ecológico que engloba informações e dicas, como o uso consciente de recursos naturais como forma de incentivar os funcionários, além de práticas de auditoria ambiental para a melhoria contínua (Silva et al., 2009). Segundos os autores, a auditoria e a política ambiental da empresa colaboram com resultados relacionados à redução de desperdícios por parte dos colaboradores e à melhoria da imagem da empresa em relação aos requisitos legais e frente aos consumidores e comunidade, resultando em certificações e reconhecimento na área socioambiental. 
A empresa avaliada neste estudo está ciente dos impactos ambientais dos seus equipamentos e materiais e cumpre com os requisitos legais do licenciamento ambiental para sua operação, porém não se envolve com o comprometimento ambiental de seus fornecedores, além de seus produtos não contarem com rotulagem ambiental. Sabe-se que o procedimento para obtenção de rótulos ambientais envolve profundo conhecimento sobre as operações industriais e o ciclo de vida do produto, bem como recursos financeiros e tempo, porém um maior conhecimento de stakeholders (clientes, fornecedores e políticas públicas) promove a formulação de produtos sustentáveis, o consumo consciente e fomenta o desenvolvimento de uma cadeia de produção com menor impacto ambiental (Oliveira Neto et al., 2015; Gomes e Casagrande Jr., 2017). Assim, muitas empresas brasileiras investem nos setores de pesquisa e inovação, práticas sustentáveis operacionais e substituições de insumo voltadas para a Produção Mais Limpa (P+L), no entanto, em apenas $13 \%$ das organizações nacionais há aplicação da rotulagem ambiental (Oliveira Neto et al., 2015).

Em relação à comunicação, existe um canal disponível, via Website, com campos específicos para o envio de sugestões e reclamações, porém a empresa não prevê, por exemplo, consulta prévia à comunidade local sobre novos investimentos ou questões ambientais, mesmo estando a 500m do bairro residencial mais próximo. Neste sentido, é importante ressaltar que, conforme Almeida e Hayashi (2020), estudos recentes da Organização das Nações Unidas (ONU) mencionam que para promover um desenvolvimento sustentável é imprescindível a construção de modelos de cooperação entre o governo, as organizações e a sociedade, com ações que adotem uma postura proativa e aberta ao diálogo, envolvendo e formando parcerias efetivas entre as partes, pois a participação comunitária não somente pode auxiliar a identificar os desafios locais existentes, mas também pode ser uma importante ferramenta para a obtenção de indicadores que apontem para as melhores alternativas para enfrentar problemas socioambientais relevantes da região (Brasil, 2009).

No tocante aos investimentos para as questões ambientais, existe um profissional responsável pelos mesmos e estes são considerados no orçamento da empresa para esta área, que é dedicado à manutenção da situação legal da empresa em relação ao meio ambiente, o monitoramento dos seus custos ambientais e a identificação de oportunidades para reduzir estes custos. Além disso, a empresa conta com locais adequados para segregação e armazenamento de resíduos sólidos, estação de tratamento de efluentes, centro de reciclagem de matéria-prima para reincorporação no processo produtivo e conservação de energia.

Mensalmente, a empresa sorteia um setor para receber uma auditoria interna, a fim de avaliar o desempenho e situações em possível desconformidade, porém sem levar em consideração os aspectos ambientais, e sim somente qualidade, saúde e segurança. Esta questão poderia ser aprimorada incluindo, por exemplo, auditorias ambientais internas, periodicamente. Apesar disso, o empreendimento tem sua eficiência energética revisada periodicamente, e encoraja o uso consciente de energia com informativos e metas de redução do consumo.

A empresa tem conhecimento da quantidade de papel utilizada como material de escritório, porém não estabelece metas para redução do consumo. Pletsch et al. (2015), aponta a preocupação com a responsabilidade ambiental a nível estratégico em empresas diversos segmentos, através do uso sustentável de recursos e boas práticas de gestão ambiental, por meio da reciclagem, redução de energia e consumo, visto a visibilidade e monitoramento de suas atividades. No entanto, o autor cita que $50 \%$ das empresas estudadas apresentam práticas para melhorar o desempenho ambiental e, apenas 35,7\% possuem ações para uso sustentável de produtos e serviços.

Os processos de produção e operação da empresa são projetados para minimizar os

impactos ambientais, porém há desenvolvimento tecnológico e avaliação de 
possibilidades de modernização voltadas apenas para a qualidade dos produtos. Este aspecto é um ponto positivo importante a ser destacado, tendo em vista que, a maioria das empresas do setor médico-hospitalar tem baixo investimento em aquisição de fontes externas de informação tecnológica em que realizam grandes investimentos em P\&D interno voltados para o desenvolvimento de novos produtos (Rieg e Alves Filho, 2003).

Em relação ao transporte e distribuição das mercadorias, não é considerado o impacto ambiental, visto que este serviço é terceirizado, não havendo uma verificação prévia das empresas prestadoras de serviço quanto às questões ambientais. Porém, a empresa acredita que este impacto é, de certo modo, levado em consideração uma vez que todas as empresas terceirizadas contratadas possuem licenciamento para realizar o transporte e distribuição, no entanto, não foi especificado se a certificação atende aos requisitos legais ambientais. De acordo com Borges (2017), a poluição atmosférica é uma das principais consequências do aumento do uso de veículos movidos à combustíveis fósseis, e traz malefícios para o meio ambiente e a saúde da população. Assim, a importância de discutir estes impactos dentro da cadeia produtiva das empresas é ressaltada.

Tratando-se da higiene e saúde ocupacional, há na empresa um serviço terceirizado especializado em engenharia de segurança e medicina do trabalho responsável pelo treinamento e gestão desta questão. A higiene é fundamental para as boas práticas na fabricação dos equipamentos e afins, e os funcionários são obrigados a higienizar as mãos de forma correta, através de procedimento padrão, assegurando a total assepsia (Silva e Pinto, 2005). Paralelamente, ao conferir segurança e bem-estar aos colaboradores, a empresa conscientiza e protege a integridade e a capacidade dos mesmos, minimizando acidentes de trabalho e doenças ocupacionais (Wachowicz 2012; Rossete, 2015).

O percentual de NSE da área de Controle Gerencial é de 72,43\%, enquadrado como "boa" segundo a classificação de Lerípio (2001). Entretanto, embora a metade dos temas ter sido enquadrado no nível de sustentabilidade "excelente", alguns temas como "política ambiental" e "transporte e distribuição" tiveram o nível classificado como "crítico". No primeiro caso, a empresa não possui uma política ambiental, portanto as quatro questões referentes a este tema não foram aplicáveis. No segundo caso, como a empresa utiliza um transporte terceirizado, não contabiliza os impactos ambientais relacionados a este tema. Uma medida que a empresa poderia adotar é dar preferência para empresas de transporte que possuam uma frota com maior eficiência energética, ou ainda, que contenham um sistema de educação dos colaboradores em relação a padrões de direção mais conscientes e com menor desperdício de energia, conforme mencionado por Martins et al. (2018).

Em relação à gestão de materiais foi verificada através de onze perguntas sobre geração, descarte, impactos ambientais dos materiais utilizados, conhecimento da empresa sobre o desempenho ambiental dos fornecedores, entre outras. Do total de respostas, três foram negativas e oito positivas. 0 percentual de NSE é de 72,73\%, sendo classificado como "bom", e os aspectos que colaboram para estes resultados são: a ausência de rotulagem ambiental, consciência e desempenho ambiental de fornecedores e serviços não levados em consideração.

\section{Gestão de efluentes}

A gestão de efluentes líquidos é estabelecida por meio do monitoramento, avaliação de custos e quantificação do consumo de água. A fim de otimizar o uso de recursos hídricos nos processos, a empresa realiza o reaproveitamento da água no sistema de refrigeração, já que o mesmo é um sistema fechado. Conforme Campos e Azevedo (2013), ações como esta, ligadas a redução do consumo e desperdício da água, ao aumento da eficiência na utilização desse recurso com a evolução de técnicas de aproveitamento ou

Rev. Bras. Gest. Amb. Sustent., 2020, vol. 7, n. 17, p. 1455-1470. 
reuso de água, que sejam economicamente viáveis, seguras e garantam a segurança e saúde de seus usuários, são essenciais para a conversação da água.

0 estabelecimento não utiliza quantidades significativas de água no seu processo industrial, conforme verificado com os gestores, a maior parte do recurso hídrico utilizado tem como destino os sanitários e higienização das mãos, porém à empresa consta com uma Estação de Tratamento de Efluentes para esgotos sanitários. 0 único efluente industrial é oriundo do gás óxido de etileno utilizado na esterilização dos produtos produzidos. Foi informado que a geração média deste efluente é de 26 mil litros por ano, sendo que o mesmo é armazenado para posterior envio para tratamento terceirizado. Este gás requer alguns cuidados especiais, pois é potencialmente carcinogênico, teratogênico e extremamente tóxico (Pinto e Saito, 1992; Sundin e Machado Neto, 2012), no entanto, esta etapa é extremamente fundamental para esterilização dos produtos que são sensíveis ao calor (Silva et al., 2005).

$\mathrm{Na}$ área de gestão de efluentes líquidos, a empresa respondeu oito questões sobre o consumo de água e o custo de geração e tratamento dos esgotos sanitários e efluentes industriais. Como resultado, devido a empresa manter uma política de redução e otimização do consumo de água, o NSE, nessa área e em seus três temas, foi enquadrado como "excelente". Segundo Beltrame et al. (2016), o despejo de efluentes em recursos hídricos está diretamente ligado à definição de sustentabilidade, pois dentre os principais fatores de degradação da qualidade da água dos corpos hídricos, a poluição por lançamento de esgotos é uma das principais. Assim, cabe destacar que uma boa gestão dos efluentes (com tratamento e destinação correta), auxilia a manter um bom funcionamento e conservação do meio ambiente.

\section{Gestão de resíduos}

A gestão de resíduos é um fator relevante para a empresa, pois ela tem conhecimento da geração, identificação, segregação e armazenamento temporário daqueles passíveis de reciclagem. A empresa possui metas para reduzir a quantidade de resíduos gerados e a equipe está ciente de suas responsabilidades quanto à disposição de resíduos.

Os resíduos de papel são enviados para cooperativas de reciclagem, ou instituições públicas que possam reutilizar, como escolas e creches municipais. De acordo com a Política Nacional de Resíduos Sólidos (PNRS) instituída pela Lei no 12.305 de 2010, as organizações devem estabelecer à elaboração do Plano de Gerenciamento de Resíduos Sólidos e a participação de cooperativas de materiais recicláveis dentro da gestão dos resíduos (Brasil, 2010).

Os resíduos perigosos, que consistem em placas eletrônicas e em um produto químico catalisador de silicone, são acondicionados e dispostos conforme determinação do órgão ambiental, em área definida, restrita e monitorada. É importante que os Resíduos de Equipamentos Eletroeletrônicos (REEE) sejam dispostos e tratados de maneira adequada, pois são caracterizados por sua baixa biodegradabilidade e composição diversificada (plásticos, vidros, metais valiosos e elementos tóxicos), o que desafia a gestão e reciclagem destes resíduos, além do alto potencial poluidor e contaminador (Panizzon et al., 2017). Já o catalizador utilizado como iniciador de polimerização é caracterizado como um produto perigoso, podendo causar irritação ocular e sensibilização à pele, além de ser inflamável e tóxico aos ambientes aquáticos, necessitando de manejo adequado quando resíduo (FISPQ, 2017).

Sobre à gestão de resíduos foram realizadas quatorze perguntas sobre geração, classificação, armazenamento, transporte e disposição final dos resíduos sólidos gerados na empresa. A organização respondeu sim para todas as perguntas desta área e o seu NSE foi enquadrado como "excelente". Segundo os entrevistados, a implementação de um sistema de logística reversa, conforme sugere a PNRS (Brasil, 2010), se encontra em 
análise, sendo este, possivelmente, o próximo passo dado pela empresa em relação a gestão de resíduos. Este é um passo importante para a empresa pois, conforme destacado por Leite (2017), no momento atual de globalização e alta competitividade, as empresas modernas reconhecem que além da busca por lucro, cada vez mais se faz necessário atender uma ampla variedade de interesses sociais, ambientais e governamentais como a implementação da logística reversa, que traz benefícios econômicos, legais, ecológicos, de cidadania e ética, entre outros.

\section{Gestão de ruídos e prevenção e controle de vazamentos}

A empresa possui mapeamento de ruídos nos limites da fábrica e no seu interior, havendo sistema de controle dos mesmos. Na área de produção, na qual há a presença de máquinas, percebeu-se que todos os funcionários utilizavam Equipamentos de Proteção Individual (EPIs). Os ruídos emitidos no interior da empresa não são percebidos na área externa. A manutenção da saúde do trabalhador é dependente da avaliação de riscos ocupacionais aos quais os profissionais estão expostos e dos investimentos por parte da empresa com o intuito de mitigar ou extinguir os fatores de risco, proporcionando à atividade laboral mais segura, sendo obrigatório o fornecimento de EPIs adequados aos riscos aos quais os profissionais são expostos (Baumgart et al., 2017).

Na área de "prevenção e controle de vazamentos" há um programa de Prevenção de Riscos Ambientais (PPRA) ao qual prioriza a manutenção de ambientes organizados com mapas e placas indicando áreas de risco e protocolos de segurança. Para a gestão de riscos, a empresa identifica dentro de suas atividades, aquelas operações que possam apresentar maior risco ambiental, assim como cenários e tomada de precauções. 0 empreendimento possui plano apropriado para contingência de acidentes e incêndios, com pessoas devidamente treinadas para estas situações.

Sobre as áreas "gestão de ruídos" e "prevenção e controle de vazamentos", foram aplicadas cinco questões que comentavam sobre a identificação de cenários, treinamento dos colaboradores em caso de emergência, mapeamento e controle de ruído. Todas as perguntas foram respondidas de maneira assertiva, de modo que o NSE nestas áreas foi enquadrado como "excelente".

\section{Conclusões}

Com relação ao NSE médio da empresa, o mesmo foi enquadrado como satisfatório, indicando boas práticas ambientais devido ao cumprimento da legislação de licenciamento ambiental e à normas de qualidade, mesmo não havendo certificações ambientais.

0 uso da adaptação do modelo GAIA auxiliou e facilitou a compreensão dos resultados da lista de verificação, e promoveu uma análise rápida sobre quais temas precisam de mais atenção com relação às práticas sustentáveis. Sua aplicação demonstrou que a organização está a poucos passos da implementação de um SGA que poderia beneficiar a mesma economicamente, tendo em vista que a busca por produtos sustentáveis no mercado aumenta a cada ano. Portanto, sugere-se a implantação de uma política ambiental, pois além de melhorar o desempenho socioambiental e empresarial, a organização terá uma maior facilidade com relação ao cumprimento da legislação. Ainda, a empresa poderia rever sua seção de "Missão, Visão e Valores", pensando em pontos positivos que a organização já possui como os relacionados a gestão de resíduos e educação ambiental dos colaboradores.

Além disso, também é importante propor, executar e participar de atividades que estimulem a criação de uma conscientização no que concerne à preservação ambiental. Uma medida estrutural interessante é a implementação de um sistema de aproveitamento de água da chuva, ou ainda, a associação do sistema à técnica de telhados verdes. Estes sistemas são vantajosos, neste caso, tendo em vista a grande área de captação que o 
telhado da empresa promove. A Lei no 13.501/2017 incluiu na Política Nacional de Recursos Hídricos o objetivo "incentivar a captação, preservação e aproveitamento de águas", o que na prática promove a criação de leis municipais e estaduais que reforçam o aproveitamento pluvial (Brasil, 2017). Deste modo, as águas pluviais podem ser direcionadas para descargas em vasos sanitários, para lavagem de pisos, calçadas e pátios, diminuindo os custos com o uso de água tratada, além de reduzir o volume de escoamento superficial que contribui para alagamentos na região.

A gestão de resíduos foi considerada a categoria com melhores práticas e políticas ambientais, percebendo-se uma intensa preocupação com este aspecto dentro da organização. Dois pontos positivos a serem destacados são: os aspectos de segregação, armazenamento e posterior doação de resíduos a cooperativas locais; e a reintrodução de parte da matéria-prima residual, recém processada e isenta de contaminação, no processo fabril.

Ademais, salienta-se que mais estudos devem ser realizados em empresas do ramo para que possam ser traçados perfis e feitas comparações, além de proporcionar um maior entendimento sobre o comprometimento das organizações com as temáticas "sustentabilidade" e "gestão ambiental".

\section{Agradecimentos}

À UFPel e ao Programa de Pós-Graduação em Ciências Ambientais - PPGCAmb, pelo incentivo à pesquisa. À empresa que participou deste estudo, pela solicitude junto à comunidade. Ao Instituto Federal de Educação, Ciência e Tecnologia pelo apoio e incentivo à capacitação. $O$ presente trabalho foi realizado com apoio da Coordenação de Aperfeiçoamento de Pessoal de Nível Superior - Brasil (CAPES) - Código de Financiamento 001.

\section{Conflito de interesses}

Os autores declaram não haver conflito de interesses.

\section{Referências}

ABIMO - Associação Brasileira da Industria de Artigos e Equipamentos Médicos, Odontológicos, Hospitalares e de Laboratório. Dados econômicos. Disponível em: <https://abimo.org.br/dados-do-setor/dados-economicos/>. Acesso em: 8 jun. 2020.

ABNT - Associação Brasileira de Normas Técnicas. ABNT NBR ISO 13485: Produtos para a saúde - Sistemas de gestão da qualidade - Requisitos para fins regulamentares. Rio de Janeiro: ABNT, 2016.

Agustini, C. A. D.; Giannetti, B. F. Avaliação de variáveis de sustentabilidade ambiental nas empresas de abastecimento de água e saneamento listadas na BM \& FBOVESPA. Gestão e Produção, v. 25, n. 4, p. 792-806, 2018. https://doi.org/10.1590/0104-530X3459-17

Almeida, R.; Hayashi, C. R. M. Avaliação empírica de um instrumento de pesquisa socioambiental: a relevância do diagnóstico participativo. Desenvolvimento e Meio Ambiente, v. 53, p. 5-24, 2020. https://doi.org/10.5380/dma.v53i0.65703

Araujo, G. C.; Bueno, M. P.; Sousa, A. A.; Mendonça, P. S. M. Sustentabilidade empresarial: conceitos e indicadores. Congresso Online Convibra, 2006. 
Barata, M. M. L.; Kligerman, D. C.; Gomez, C. M. A gestão ambiental no setor público: uma questão de relevância social e econômica. Ciência \& Saúde Coletiva, v. 12, n. 1, p. 165-170, 2007.

Barbieri, J. C. Gestão ambiental empresarial: conceitos, modelos e instrumentos. 4. ed. São Paulo: Saraiva, 2016.

Baumgart, B. Z.; Macedo, A. B. T.; Bortoletti, A. P. G.; Souza, S. B. C. Riscos ocupacionais e equipamentos de proteção individual em Bombeiros da Brigada Militar. Ciência \& Saúde, v. 10, n. 1, p. 28-33, 2017.

Beltrame, T. F. Beltrame, A. F.; Lhamby, A. R.; Pires, V. K. Efluentes, resíduos sólidos e educação ambiental: uma discussão sobre o tema. Revista Eletrônica em Gestão, Educação e Tecnologia Ambiental, v. 20, n. 1, p. 283-294, 2016.

Borges, T. C. Meios de transporte utilizados e a contribuição para a Pegada de Carbono. Curitiba: Universidade Tecnológica Federal do Paraná, 2017. (Trabalho de Conclusão de Curso).

Brasil. Lei no 12.305, de 2 de agosto de 2010. Institui a Política Nacional de Resíduos Sólidos; altera a Lei no 9.605, de 12 de fevereiro de 1998; e dá outras providências. Disponível em: <http://www.planalto.gov.br/ccivil_03/_ato2007-2010/2010/lei/ l12305.htm>. Acesso em: 20 jul. 2019.

Brasil. Lei no 13.501, de 30 de outubro de 2017. Altera o art. $2^{\circ}$ da Lei $\mathrm{n}^{\circ} 9.433$, de 8 de janeiro de 1997, que institui a Política Nacional de Recursos Hídricos, para incluir o aproveitamento de águas pluviais como um de seus objetivos. Disponível em: <http://www.planalto.gov.br/ccivil_03/_ato2015-2018/2017/lei/L13501.htm>. Acesso em: 20 jul. 2019.

Brasil. Lei no 6.360, de 23 de setembro de 1976. Dispõe sobre a vigilância sanitária a que ficam sujeitos os medicamentos, as drogas, os insumos farmacêuticos e correlatos, cosméticos, saneantes e outros produtos, e dá outras providências. Disponível em: <http://www.planalto.gov.br/ccivil_03/leis/16360.htm>. Acesso em: 20 jul. 2019.

Brasil. Ministério das Cidades. Caderno metodológico para ações de educação ambiental e mobilização social em saneamento (PEAMSS). Brasília: Ministério das Cidades, Secretaria Nacional de Saneamento Ambiental, 2009. Disponível em: <http://www.mma.gov.br/images/arquivo/80219/CadernoMetodologico.pdf>. Acesso em: 20 jul. 2019.

Brasil. Resolução da Diretoria Colegiada - RDC no 16, de 28 de março de 2013. Aprova o Regulamento Técnico de Boas Práticas de Fabricação de Produtos Médicos e Produtos para Diagnóstico de Uso in vitro e dá outras providências. Disponível em: <https://bvsms.saude.gov.br/bvs/saudelegis/anvisa/2013/rdc0016_28_03_2013.pdf>. Acesso em: 8 jun. 2020.

Campos, L. M. S.; Lerípop, A. Á. Auditoria ambiental: uma ferramenta de gestão. São Paulo: Atlas, 2009.

Campos, L. M. S.; Melo, D. A. Indicadores de desempenho dos Sistemas de Gestão Ambiental (SGA): uma pesquisa teórica. Produção, v. 18, n. 3, p. 540-555, 2008. https://doi.org/10.1590/S0103-65132008000300010

Campos, M. M.; Azevedo, F. R. Aproveitamento de águas pluviais para consumo humano direto. Jornal Eletrônico - Faculdades Integradas Vianna Júnior, v. 5, n. 1, p. 23-42, 2013. Disponível em: <https://www.jornaleletronicofivj.com.br/jefvj/article/view/501>. Acesso em: 20 jul. 2019. 
Capelari. M. G. M.; Borinelli, B.; Vieira, S. F. A.; Rodrigues, E. M. A internalização da variável ambiental nas indústrias do Paraná (1970 a 2006): uma análise neoinstitucional da relação entre política ambiental e indústria. Desenvolvimento e Meio Ambiente, v. 27, p. 145-161, 2013. https://doi.org/10.5380/dma.v27i0.28853

Dias, R. Gestão ambiental: responsabilidade social e sustentabilidade. 3. ed. São Paulo: Atlas, 2017.

Fagundes, C.; Schreiber, D. Concepção de um modelo para avaliação da sustentabilidade no processo produtivo do suco de uva orgânico. Desenvolvimento e Meio Ambiente, v. 41, p. 57-82, 2017. https://doi.org/10.5380/dma.v41i0.49766

FISPQ - Ficha de Informação de Segurança de Produto Químico. PERKADOX L-W75. Multichemie: 2017. Disponível em: <http://www.multichemie.com.br/images/pdf/ 841708a6fdb877b05155a55345877701.pdf>. Acesso em: 17 jul. 2019.

Godini, M. D. Q.; Valverde, S. Gestão integrada de qualidade, segurança \& saúde ocupacional e meio ambiente. São Paulo: Bureau Veritas Brasil, 2001.

Gomes, N. S.; Casagrande Jr., E. F. 0 conhecimento e o ponto de vista de 52 empresas brasileiras a respeito da rotulagem ambiental de produtos. Design \& Tecnologia, v. 13, 2017.

Grael, P. F. F.; Oliveira, O. J. Sistemas certificáveis de gestão ambiental e da qualidade: práticas para a integração em empresas do setor moveleiro. Produção, v. 20, n. 1, p. 30-41, 2010. https://doi.org/10.1590/S0103-65132010005000017

Hrdlicka, H. A. As boas práticas de gestão ambiental e a influência no desempenho exportador: Um estudo sobre as grandes empresas exportadoras brasileiras. São Paulo: Universidade de São Paulo, 2018. (Tese de doutorado).

La Rovere, E. M.; D’Avignon, A.; Pierre, C. V.; Kligerman, D. C.; Silva, H. V. O.; Barata, M. M. L.; Malheiros, T. M. M. Manual de auditoria ambiental. 3. ed. Rio de Janeiro: Qualitymark, 2011.

Leite, P. R. Logística reversa: sustentabilidade e competitividade. São Paulo: Saraiva Educação, 2017.

Lerípio, A. A. GAIA: um método de gerenciamento de aspectos e impactos ambientais. Florianópolis: Universidade Federal de Santa Catarina, 2001. (Tese de doutorado).

Martins, A. P.; F. Junior, C.; Amaral, E.; Silva, S.; Farias, W. Gestão da eficiência energética e sustentabilidade: um estudo de caso na Kicaldo e Lanza Transportes. Goiânia: Fundação Dom Cabral, Instituto de Transporte e Logística, 2018. (Trabalho de conclusão de curso de especialização).

Mazzer, C.; Cavalcanti, O. A. Introdução à gestão ambiental de resíduos. Infarma - Ciências Farmacêuticas, v. 16, n. 11/12, 2013.

Mendes, G. H. S.; Toledo, J. C. Gestão do pré-desenvolvimento de produto: estudo de casos na indústria de equipamentos médico-hospitalares. Produção, v. 22, n. 3, p. 391-404, 2012. https://doi.org/10.1590/S0103-65132012005000031

Nascimento, L. F. Gestão ambiental e sustentabilidade. Florianópolis: Departamento de Ciências da Administração - UFSC; Brasília: CAPES: UAB, 2012.

Oliveira Neto, G. C.; Godinho Filho, M.; Ganga, G. M. D.; Naas, I. A.; Vendrametto, 0. Princípios e ferramentas da produção mais limpa: um estudo exploratório em empresas brasileiras. Gestão \& Produção, v. 22, n. 2, p. 326-344, 2015. https://doi.org/ 10.1590/0104-530X1468-14 
Oliveira, 0. J. Guidelines for the integration of certifiable management systems in industrial companies. Journal of Cleaner Production, v. 57, p. 124-133, 2013. https://doi.org/10.1016/j.jclepro.2013.06.037

Panizzon, T.; Reichert, G. A.; Svhineider, V. E. Avaliação da geração de resíduos de equipamentos eletroeletrônicos (REEEs) em uma universidade particular. Engenharia Sanitária e Ambiental, v. 22, n. 4, p. 625-635, 2017. https://doi.org/10.1590/s141341522017142636

Paz, F. J. Indicadores para a sustentabilidade organizacional: um estudo exploratório para o desenvolvimento de um sistema computacional. Santa Cruz do Sul: Universidade de Santa Cruz do Sul, 2015. (Dissertação de mestrado).

Pheng, L. S.; Tan, J. H. K. Integrating ISO 9001 Quality Management System and ISO 14001 Environmental Management System for contractors. Journal of Construction Engineering and Management, v. 131, n. 11, 2005. https://doi.org/10.1061/ (ASCE)0733-9364(2005)131:11(1241)

Pieroni, J. P.; Reis, C.; Souza, J. O. B. A indústria de equipamentos e materiais médicos, hospitalares e odontológicos: uma proposta de atuação do BNDES. 2010. Disponível em: <http://www.bndes.gov.br/SiteBNDES/export/sites/default/bndes_pt/Galerias/Arquivos /conhecimento/bnset/set3105.pdf>. Acesso em: 17 jul. 2019.

Pinto, T. J.; Saito, T. Esterilização por óxido de etileno. II. Influência de corpos de prova no desempenho de monitores biológicos e sua avaliação. Revista de Saúde Pública, v. 26, n. 6, p. 384-391, 1992.

Pletsch, C. S.; Bringhenti, J.; Silva, A.; Rosa, F. S. Perfil da evidenciação ambiental das empresas listadas no índice de sustentabilidade empresarial. Revista Contabilidade Vista \& Revista, v. 25, n. 3, p. 57-77, 2014.

Richard Júnior, L. Modelo para implementação de sistema integrado de gestão ambiental para a carcinicultura marinha. Florianópolis: Universidade Federal de Santa Catarina, 2006. (Tese de doutorado).

Rieg, D. L.; Alves Filho, A. G. Esforço tecnológico e desempenho inovador das empresas do setor médico-hospitalar localizadas em São Carlos, SP. Gestão \& Produção, v. 10, n. 3, p. 293-310, 2003. https://doi.org/10.1590/S0104-530X2003000300006

Rosa, F. S.; Costa, G. D.; Pfitscher, E. D.; Lunkes, R. J. Termômetro ambiental: um estudo sobre níveis de comprometimento e desempenho da gestão ambiental de uma empresa do setor têxtil do estado de Santa Catarina. Revista Ambiente Contábil, v. 4, n. 2, p. 18-39, 2012.

Rossete, C. A. Segurança e higiene do trabalho. São Paulo: Pearson Education do Brasil, 2015.

Santos, A. A. P.; Wolter, A.; Sehmem, S.; Gomes, C.; Santana, G. Gestão da cadeia de suprimentos sustentável: uma análise de uma indústria madeireira. Teoria e Prática em Administração, $\quad$ v. 8, $\quad$ n. 1, p. 160-189, 2018. https://doi.org/10.21714/2238104X2018v8i1-36854

Santos, G. S.; Sehmem, S.; Freitas, M. S. Avaliação do nível de sustentabilidade de um curtume gaúcho à luz do sistema de gestão ambiental (SGA). Revista de Gestão Ambiental e Sustentabilidade, v. 4, n. 2, p. 102-117, 2015.

Silva, F. R. C.; Luca, M. M. M.; Corrêa, D. M. M. C.; Oliveira, M. C. A auditoria ambiental como instrumento gerencial de apoio à preservação do meio ambiente. Sociedade, Contabilidade e Gestão, v. 4, n. 2, p. 72-87, 2009. 
Silva, M. V.; Pinto, T. J. Reutilização simulada de produtos médico-hospitalares de uso único, submetidos à esterilização com óxido de etileno. Revista Brasileira de Ciências Farmacêuticas, v. 41, n. 2, p. 182-189, 2005.

Silva, R. M.; Sandri, A. P. G.; Nakano, V.; Nishiyama, S. A. B. Utilização do óxido de etileno para esterilização de material médico-hospitalar. Revista UNINGA, v. 4, p. 109-122, 2005.

Silveira, M. C. A. C. Responsabilidade social empresarial e a sustentabilidade. São Paulo: Annablume, 2011.

Stefano, N. M. Abordagem conceitual de Sistema Integrado de Gestão (SIG) na busca pela melhoria contínua nas organizações. Maringá Management: Revista de Ciências Empresariais, v. 6, n. 1, p. 7-15, 2009.

Sundin, M. S.; Machado Neto, V. Esterilização a óxido de etileno: uma revisão. Anais do XIII Congresso Brasileiro de Engenharia Biomédica, Porto de Galinhas, CBEB, 2012.

Teles, C. D.; Dutra, C. C.; Ribeiro, J. L. D.; Guimarães, L. B. M. Uma proposta para avaliação da sustentabilidade socioambiental utilizando suporte analítico e gráfico. Produção, v. 26, n. 2, p. 417-429, 2016. https://doi.org/10.1590/0103-6513.0638T6

Wachowicz, M. C. Segurança, saúde e ergonomia. 1. ed. Curitiba: Intersaberes, 2012.

Informação da Licença: Este é um artigo Open Access distribuído sob os termos da Licença Creative Commons Attribution, que permite uso irrestrito, distribuição e reprodução em qualquer meio, desde que a obra original seja devidamente citada. 